\section{Australian Journal of \\ Crop Science}

AJCS 14(08):1221-1229 (2020)

doi: 10.21475/ajcs.20.14.08.p2184
AJCS

ISSN:1835-2707

\title{
Comparison of methods for the extraction of proteins from root and leaf tissue of sugarcane (Saccharum spp.) for proteomic analysis
}

\author{
Luciana da Silva Viana ${ }^{1}$, Paulo Pedro da Silva ${ }^{2}$, Velber Xavier Nascimento ${ }^{1}$, Alessandro Riffel ${ }^{3}$ and Antônio \\ Euzébio Goulart Sant'Ana²
}

${ }^{1}$ Centro Universitário CESMAC, Rua Conego Machado, Farol, 57051-160, Alagoas, Brazil

${ }^{2}$ Universidade Federal de Alagoas, Campus A. C. Simões, Centro de Ciências Agrárias, Laboratório de

Pesquisas em Recursos Naturais, Av. Lourival Melo Mota, s/n, Tabuleiro do Martins, 57072-970, Maceió, Alagoas, Brazil

${ }^{3}$ Embrapa Tabuleiros Costeiros, Tabuleiro do Martins, P.O. Box 2013, 57061-970, Maceió, Alagoas, Brazil

\section{*Corresponding author: velberxavier@gmail.com}

Abstract

\begin{abstract}
The extraction of proteins from plants is a crucial procedure for successful protein determination such as purification, separation, and mass spectrometry. Protein extraction from plant tissues is generally difficult due to the presence of various molecules (cell wall, polysaccharides, and lipids) and interfering compounds. For this reason, the step of separation of proteins is a big challenge in obtaining good results in plant proteomic studies, notably from sugarcane. The current study assesses three extraction methods to prepare protein samples for proteomic analysis. Method 1 (control): TCA/acetone, method 2: TCA/acetone modified and Method 3: Phenol/SDS/ammonium acetate. Plants of cultivar RB92579 were grown in 10L pots under ideal humidity conditions in a greenhouse for 60 days. Samples collected on leaves +1 and roots were carried out using nitrogen and stored in an ultra-freezer at $80^{\circ} \mathrm{C}$ for later use in proteome assays. For the tested methods, a comparison was made between the quantitative and qualitative data obtained from the tissue of sugarcane leaves and roots. According to the results obtained, methods 2 and 3 produced the best yield in the extraction of total proteins from the leaves and roots of sugarcane, when compared to (control) method 1 (TCA/acetone). This can be observed when comparing the quantitative and qualitative data obtained using the different extraction methods. By comparing methods 2 and 3, the latter showed a massive gain of extracted proteins much greater than the first method, mainly when the extraction of total proteins from the roots are compared. Similarly, the 2-DE gels run after using method 3 showed less background, compared to method 2. Another observation was the presence of different "spots" in the 2-DE gels between the samples extracted using methods 2 and 3. Method 3 (phenol / SDS / ammonium acetate) presented better results for extraction of proteins and in the 2-DE gels, with a greater number of total and specific "spots", greater reproducibility and less background. This method could be utilized as the standard method for proteomic studies in sugarcane.
\end{abstract}

Keywords: Protein extraction; two-dimensional electrophoresis; leaves and roots tissue.

Abbreviations: 2DGE_Two_dimensional (2_D) gel electrophoresis, CHAPS_Chloroamidopropryl dimethylammonio propane sulfonate, DTT_Dithiothreitol, IEF_Isoelectric focusing, LC_Liquid chromatography , LC-MS/MS_Chromatography tandem mass spectrometry, MALDI TOF/TOF_Matrix_assisted laser desorption ionization source and tandem time_of_flight, NADP_Nicotinamide adenine dinucleotide phosphate, PMSF_Phenylmethylsulfonyl fluoride, PVPP_Polyvinylpolypyrrolidone, SDS_Sodium Dodecyl Sulfate, TCA_Trichloroacetic acid.

\section{Introduction}

The cultivation of sugarcane is of great importance in tropical and subtropical regions, for the production of sweeteners, alcoholic beverages, biofuels, and other biobased chemicals. Although Brazil and India produce more than half of the world's sugar cane, the crop is grown commercially in over 50 countries on 5 continents (Pryor et al., 2017). Proteomics is the analysis of the complete set of proteins produced in a cell, at a given time. In proteomics, several different aspects of protein analysis are covered, including the analysis of protein expression (Goez et al., 2018).

For a long time, the most used technique in comparative proteomic studies was the two-dimensional gel electrophoresis (2-DE) (Magdeldin et al., 2014). This technique can analyze thousands of proteins in a single run, including the theoretical capability to separate about ten 
thousand proteins. With many advances in the field of 'omics', proteomic analysis has developed rapidly, mainly by separating proteins into two-dimensional gel to chromatographic techniques, based on coupled gel-free shotgun liquid chromatography tandem mass spectrometry (LC-MS/MS) platforms (Hu et al., 2015).

A comprehensive description of the proteome of an organism provides not only a catalog of all the proteins that are being expressed by the genome, but also the expression of the proteins under defined conditions and the distribution of certain proteins within the cell (Gygi et al., 2000).

Extraction of total protein from plant tissues is a crucial step to identify polypeptide fractions associated with metabolic processes. Different procedures for protein extraction have been reported for different tissues and plant species to obtain protein fractions which are adequate for purification, separation, and identification of proteins (Maranho et al., 2018; Jorrin-Novo et al., 2015).

The different parts of the plants may have greater amount of interfering compounds, mainly phenolic pigments, polysaccharides, terpenes and organic acids (Gygi et al., 2000). These compounds are mainly accumulated in the vacuole in their soluble form, which can be extracted along with the proteins. Therefore, affect the quality and resolution of 2-DE and also their separation by chromatography (Herbert, 1999). Various methods of protein extraction have been developed and adapted for use in proteomic studies for a range of crops, such as rice (Oryza spp.), maize (Zea mays L.) and soybean (Glycine max) (Dooki et al., 2006; Li et al., 2007; Xu et al., 2008). So far, a few appropriate protocols are available for the extraction of proteins of sugarcane (Saccharum spp.) known as the sugarcane tissues have greater rigidity, a fibrous nature, extreme levels of oxidative enzymes, phenolic compounds, carbohydrates and other types of metabolites that interfere in extraction (Maranho et al., 2018; Wang et al., 2006). Thus, the methodology of sample preparation should be compatible with the downstream proteomic strategies for separation, identification and analysis, which will allow obtaining of maximum coverage of proteins present in a complex protein mixture, leading to a deep proteomic analysis (Agrawal et al., 2011). Due to the economic importance of sugarcane, the need for understanding the specific physiological processes and the lack of studies involving the proteome of this crop is necessary. The aim of this study was to test an effective methodology for the extraction of total proteins from the leaf tissue and roots of sugarcane with a target to obtain protein extract without interfering proteomic analysis from the reproducibility presented by 2-DE. The sugarcane protocols have often been specific and focused on the preparation of samples for proteomics from young and sensitive plant tissues that are most often grown in the laboratory, requiring a universal extraction protocol. There is also need for extraction of proteins from mature plant stages, such as roots in field grown environment containing soil substrate. In this case, we need a method that could be able to efficiently remove non-protein substances from sample tissues (Niu et al., 2018b; Gang et al., 2014), and particularly group of secondary compounds, such as phenolics, lipids, pigments, organic acids, and carbohydrates, which greatly interfere with protein extraction and proteomic analysis (Wang et al., 2008). The objective of this study was to establish an appropriate protocol for total protein extraction from the tissue of leaves and roots of sugarcane in order to obtain a high concentration and purity, a higher number of spots, high reproducibility, and higher resolution for gels.

\section{Results and Discussion}

\section{Quantitative analysis of protein extractions}

The success of a proteomic study of any organism relies primarily on an efficient extraction step. The result in terms of the quantity and quality of the proteins will depend mostly on the choice of the extraction method adopted for the type of studied tissue because this directly influences the isoelectric focusing (Görg et al., 2008). Currently, various proteomic approaches are being explored extensively, in which they mainly involve gel-based and gel-free techniques, including label-based and label-free protein quantification (Komatsu, 2019). Although advanced protein detection techniques, especially LC-MS / MS, can greatly increase identification sensitivity and reliability, protein extraction still remains a challenge because sample quality is considered critical to the coverage, reliability and productivity of the protein. The proteomic analysis and most of the extracted proteomes are shaped by the extraction methods (Niu et al., 2018a, 2018b).

Table 1 contains the data for the quantification of total proteins obtained from the tissue of sugarcane leaves and roots using three different extraction buffers described for other species, such as olives (Olea europea L.) (Shen, 2002) and rice (Oryza sativa L.) (Görg et al., 2008). According to the results obtained, methods 2 and 3 presented a greater yield in the extraction of total proteins from leaves and roots. Method 3 showed to be even more effective in the extraction of proteins from root tissue, with a protein yield five times higher as compared to method 2. Protein extraction from the roots using trichloroacetic acid/acetone method (method 1) was not performed because this method, even for leaf tissues, resulted in a substantially lower protein yield (Table 1). This low yield could be due to the incomplete removal of interfering compounds, mainly phenolic compounds and carbohydrates. The tissue extracts obtained by this method were also excluded from 2-DE gel analysis because of low yield. Protein extraction with TCA / acetone has been shown to be more efficient in younger tissues, as they have few interfering compounds, such as immature stage tissues (Maranho et al., 2017), making their application more restricted. The tissues at more advanced stages of sugarcane development, mainly roots, are grown in substrates containing soil or directly in the field under real cultivation conditions, have substantially limited use in proteomic studies.

\section{Analysis of extracts by two-dimensional electrophoresis (2-} $D E)$

First, all samples of the leaf tissues were macerated into a fine powder using mortar, pestle, and liquid nitrogen and homogenized in the $40 \mathrm{mM}$ Tris- $\mathrm{HCl}$ buffer $(\mathrm{pH}$ 7.5) for two 
hours. This step minimized proteolysis and other forms of the degradation of proteins and enable resolubilization of the proteins in the extract (Xu et al., 2008). Three protein extractions were carried out for methods 2 and 3 (Figure 1). The proteins obtained were subjected to two-dimensional electrophoresis using an IPG with a $\mathrm{pH}$ range of 3-10 for isoelectric focusing (IEF) followed by SDS-PAGE (Fig $1 \mathrm{~A}$ and $1 B)$. We observed that most of the proteins were localized in the regions between $\mathrm{pH} 4$ and 7 . Modifications in the IEF in these conditions may have affected the biochemical characteristics of the protein extracts from the tissues of sugarcane reducing the number of spots outside the $\mathrm{pH}$ range (Shen, 2002).

To improve the separation and resolution of proteins in the gel an IPG with $\mathrm{pH}$ gradient ranging from 4-7 was used. With this modification in IEF, there was a significant improvement in the quantity and the resolution of the spots in the gel. The average total number of spots detected in gels for method 2 was $179 \pm 0.6$ (Figure $2 \mathrm{~A}$ ) and method 3 was $517 \pm 61$ (Figure 2B). After automatic detection with ImageMaster 2D Platinum software, a manual editing with corrections was done. Thirty-four spots were detected in common between extraction methods 2 and 3: 145 unique spots in method 2 and 484 unique spots for method 3.

The same extraction procedures were applied for root tissues. The average total number of spots detected on 2-DE from root tissue using method 3 was $633 \pm 69$ (Figure 2C).

The extraction method 2 showed a higher frequency (> 50\%) of proteins with the $\mathrm{pl}$ in the range of 5-6 and $>35 \%$ for proteins with a molecular mass of $<40 \mathrm{kDa}$ (Figure 3). Method 3 showed a frequency of spots $>25 \%$ in proteins with the $\mathrm{pl}<5-7$ and $>20 \%$ in molecular weight ranges $>40$ $\mathrm{kDa}$. Thus, method 2 was more efficient than method 3 in the separation of proteins with the $\mathrm{Mr}<40 \mathrm{kDa}$, while both methods were effective in the separation of proteins with a $\mathrm{pl}$ in the range of 5-6.

The method of using TCA / acetone modified has been used extensively in 2-DE analysis for different plant tissues from various species such as Arabidopsis thaliana, rice (Oryza sativa), soybean (Glycine max) and corn (Zea mays) (Li et al., 2007; Xu et al., 2008; Wang, 2006). Trichloroacetic acid (TCA) is the first choice for extracting proteins from plant tissues due to its ease of use, speed, high reproducibility, and good resolution of spots of various ranges of molecular weight and $\mathrm{pH}$ (Wang et al., 2003). Despite all of its advantages, the re-solubilization of proteins extracted by this method is difficult and inefficient due to prolonged incubation in TCA/acetone, in addition to requiring complete tissue pulverization and repeated washes (Niu et al, 2018b). According to Saravanan and Rose, (2004) usage of the TCA/acetone modified (method 2) contained less proteins (mg/g fresh weight) in the extracts obtained from leaves, roots and flowers of plants such as banana (Musa spp.), orange (Citrus spp.) Avocado (Persea spp.), and tomato (Solanum spp.). However, the method of extraction with SDS / phenol / ammonium acetate (method 3) resulted in extracts with higher amounts of protein and better resolution in 2-DE, including those with high molecular weights. These differences between the methods may be due to some factors, such as: (a) different degrees of solubility as a result of the biochemical characteristics of the proteins, (b) different degrees of proteolysis undergone by the proteins in each extraction method, or (c) by subcellular localization of proteins that are differentially disrupted by each extraction method (Wang et al., 2003). Isaacson et al. (2006) used the method of extraction with phenol and obtained good quality gels for root tips of maize. Likewise, Raharjo et al. (2004) used the same method and obtained good results in experiments using two-dimensional gels. Thus, the extraction of proteins using SDS / phenol / ammonium acetate (method 3) has been the preferred method for most recalcitrant plant tissues (Wang et al., 2003), like the sugarcane leaf and root tissues in this study. Phenol usage is most effective for removal of unwanted interfering substances from the protein samples of recalcitrant plant tissues (He and Wang, 2008; Pavokovic' et al., 2012). It has been reported that for recalcitrant tissues, acetone and TCA / acetone precipitation do not sufficiently remove nucleic acids, carbohydrates, and polyphenols, which cause co-precipitation and degradation of proteins. The method of using phenol, although more laborious and time-consuming, resulted in higher protein yield and less contamination than those samples of the TCA / acetone precipitation method with protein extractions from recalcitrant tissues (Pavokovic' et al., 2012). Using 2-DE or LC, removes contaminated compounds that are mixed in the macerated tissue, which is another crucial step in proteomic analysis. Removing these interfering compounds always involves the use of organic solvents such as acetone or $10 \%$ TCA in acetone (Zhou et al., 2002). For this study, a washing step with methanol in the presence of ammonium acetate was introduced as this is often used in the removal of phenolic compounds. The latter neutralizes the TCA residues and increases the $\mathrm{pH}$, facilitating the extraction of proteins with phenol (Crozier et al., 1997). Therefore, this study shows 2-DE gel patterns of proteins from the leaves and roots tissues with high quality, free of stains background and streaks, and with well resolved spots throughout the gel, which is hardly achieved for sugarcane; especially when the used material is root tissue.

\section{Analysis of proteins obtained by MS/MS}

To confirm the quality of protein extracts obtained using method 3 and after 2-DE, some spots were randomly selected for identification by MALDI TOF/TOF mass spectrometry. The majority of spots produced good quality spectra allowing the identification of the protein (Figure 4).

Proteome studies of sugarcane (Saccharum spp.) by using 2DE have yet to be described completely. Consequently, specific protocols for the protein extractions from sugarcane tissues are scarce. This is one of the more relevant steps by strongly influencing 2-DE and LC. Therefore, samples containing high purity protein extracts and concentration are critical for success in both separation techniques and mass spectrometry sequencing. In this study, 3 different extraction methods of proteins from leaf and root tissue were adapted from other plant species protocols, and its application to 2-DE was tested. Among the methods tested, the method using phenol/SDS/ ammonium acetate (method 3) showed the higher amount of extracted proteins per fresh tissue, for leaves and root tissues. When 
Table 1. Quantification of proteins for the three extraction methods in sugarcane leaves and roots tissues. Method 1(control): TCA / acetone, Method 2: TCA /acetone modified, and Method 3: SDS / phenol / ammonium acetate. The results are expressed as mean \pm standard deviation $(n=3)$. Values indicated in row are statistically different by the Tukey test at 0.05 probability.

\begin{tabular}{llcl}
\hline Tissues & Production of proteins & (mg/g fresh mass) & \\
& Method 1 & Method 2 & Method 3 \\
Leaves & $13.33 \pm 0.72^{\mathrm{a}}$ & $17.26 \pm 0.64^{\mathrm{b}}$ & $22.41 \pm 0.46^{\mathrm{c}}$ \\
Roots & Not done & $5.10 \pm 0.30^{\mathrm{a}}$ & $24.98 \pm 1.20^{\mathrm{b}}$ \\
\hline
\end{tabular}
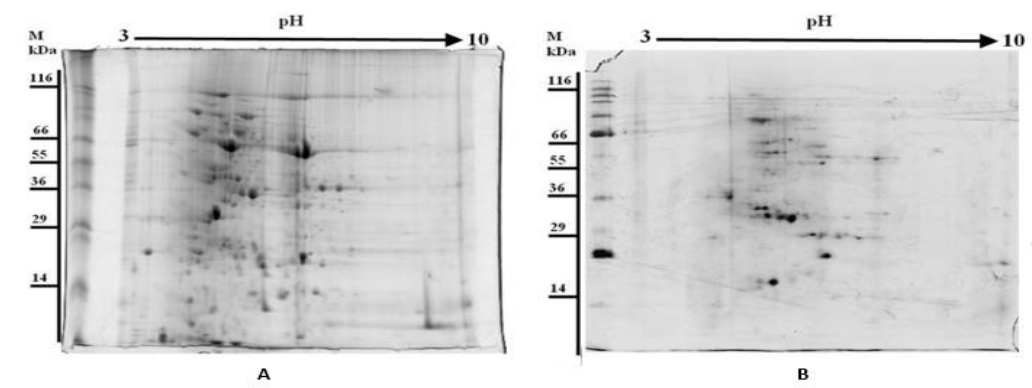

Fig 1. 2-DE gel of total protein using the method with method 2 (TCA /acetone modified). Isoelectric focusing was carried out in a linear gradient of pH 3-10 and stained with Coomassie Brilliant Blue G-250. Protein from leaf tissues (A) and roost (B) of sugarcane.

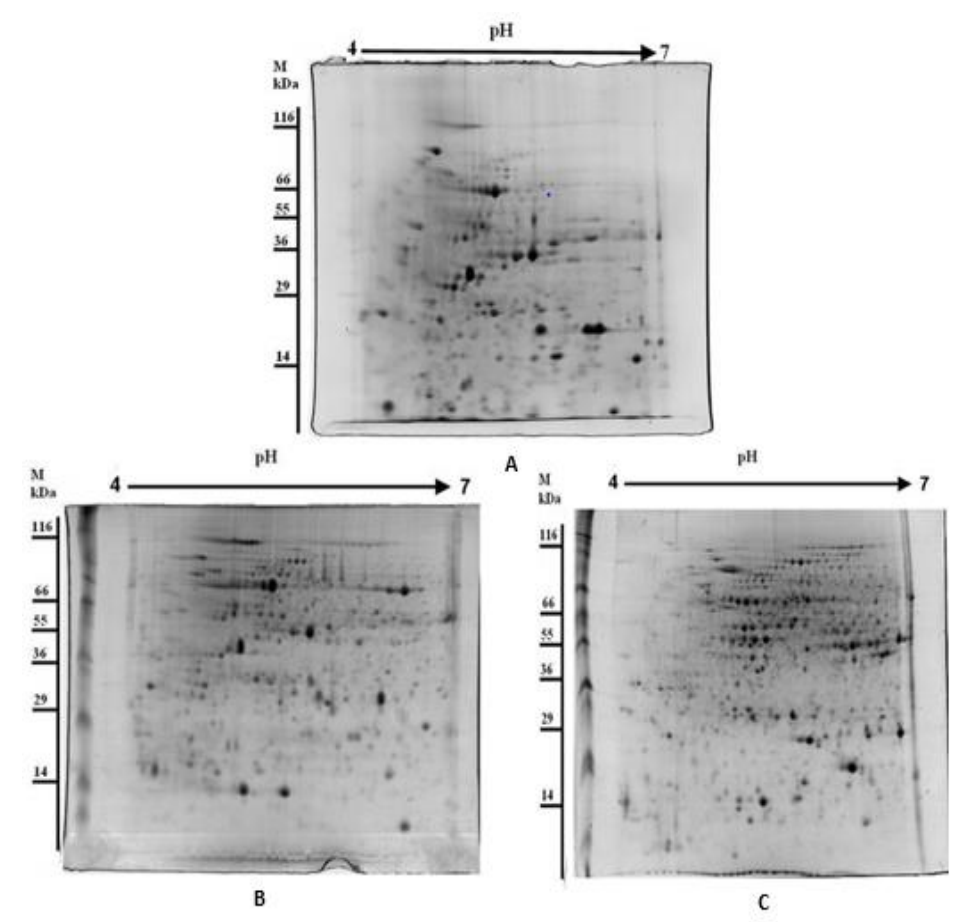

Fig 2. 2-DE gel of total proteins from leaves of sugarcane using different methods. Method 1: TCA/acetone (control) (A), Method 2: TCA /acetone modified (B) and Method 3: SDS / phenol / ammonium acetate (C). Isoelectric focusing carried out in a linear gradient of $\mathrm{pH} 4-7$, stained with Coomassie Brilliant Blue G-250.
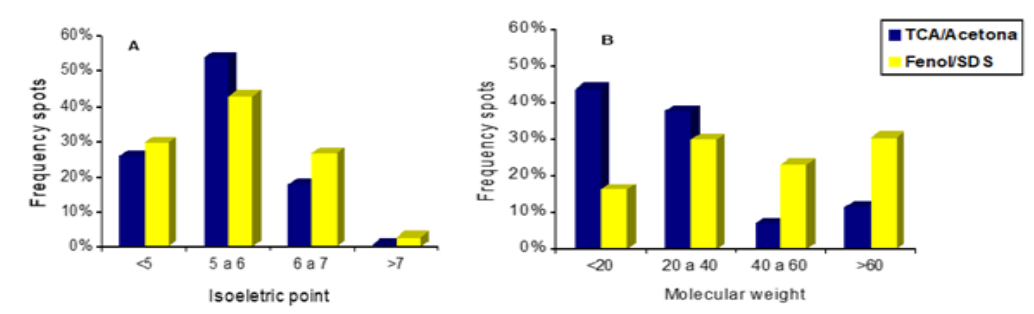

Fig 3. Characterization of spots from the tissue of leaves of sugarcane obtained with the methods TCA / acetone modified (method 2 ) and SDS / phenol / ammonium acetate (method 3) in different ranges of isoelectric point (A) and molecular weight (B). 

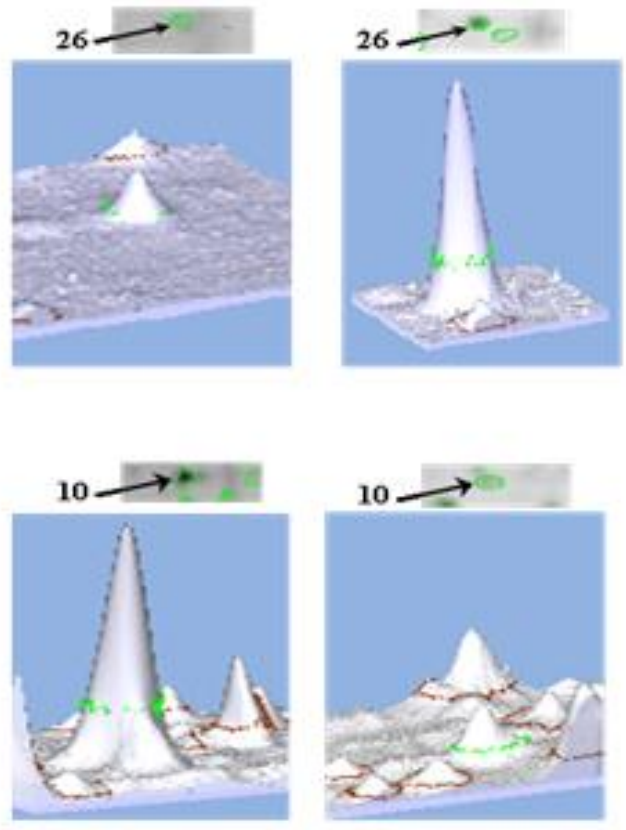

A: TCA

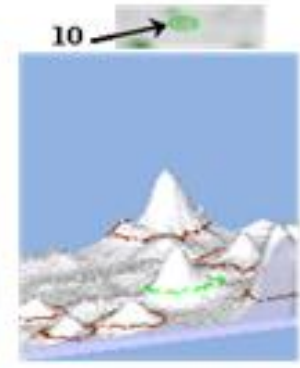

B: Phenol/SDS

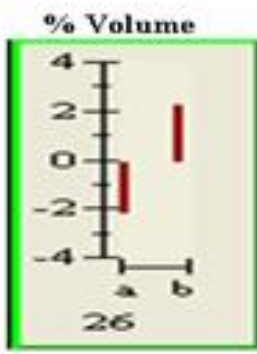

Spot 26

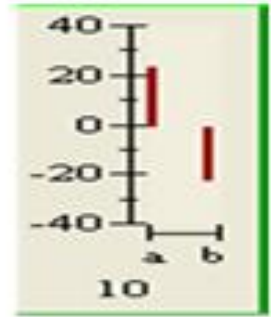

Spot 10

Fig 4. Quantitative analysis of some selected spots per \% volumes calculated between the methods using TCA / acetone modified (method 2) and SDS / phenol / ammonium acetate (method 3) $(p<0.01)$. Extracted spots that were statistically different by the method 2 (A) and extracted spots that were differentiated by the method 3 (B). The 3D images (left) represent the projection of the expression intensity of the same spots present in the 2-DE gels for method 2 (A) and method 3 (B), whose bar graph (right) shows the intensity of volume (\%) of the respective spots number 10 and 26 present in both methods, showing that the expression intensity of spot 10 was twenty times higher in A compared to B, whereas for spot 26 the intensity of expression was twice lower in A compared to $\mathbf{B}$

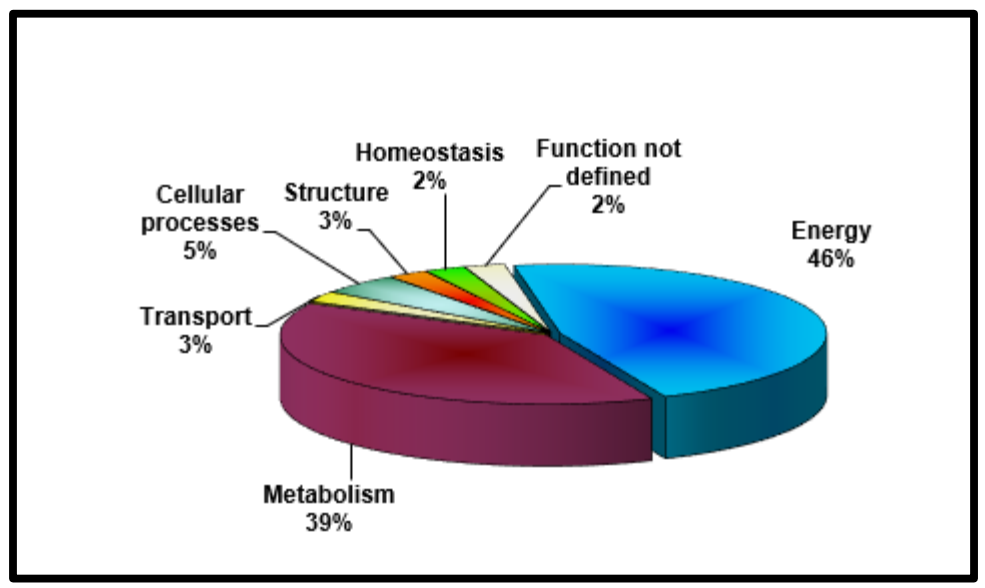

Fig 5. Functional classification of analyzed spots separated by two-dimensional electrophoresis and sequenced by MS / MS.

submitted to 2-DE, the gels obtained by method 3 showed the higher number of spots distributed evenly throughout the gel with excellent migration quality without stains or smears. Therefore, the use of this method was efficient in the removal of contaminants interfering in both IEF and SDSPAGE. In addition, most spots submitted to mass spectrometry were successfully identified. It was possible to identify the protein content of 80 of the 180 spots analyzed using the MASCOT database as described in the methods. The unidentified spots produced low resolution mass spectra or with a large background and made it impossible to sequence and identify the protein. Among the identified proteins, a large number of proteins showed identity with protein sequences from plant species such as Zea mays and Sorghum bicolor. These species have a large number of protein sequences and genes deposited in public databases such as the NCBI and are genetically related to sugarcane. We identified 38 spots that showed homology with Saccharum Officinarum proteins or cDNAs already deposited in databases.

Based on data generated by the functional genome project of sugarcane (SUCEST), proteins such as chaperonins, 3-beta 
hydroxysteroid dehydrogenase, triosephosphate isomerase, and ferredoxin NADP reductase were extracted. Ubiquitinconjugating enzyme, which is involved in metabolic processes and defense of abiotic stress in plants, was also obtained.

The proteins identified in the present study obtained from method 3 were classified according to their biological function in functional categories and their distribution is represented in Figure 5. The most representative classes in genotype used in the present study (RB92579) were the proteins involved in metabolism and energy.

Sugarcane had its functional genome sequenced (Vetorre et al., 2001) with 237,954 sequences of ESTs (expression sequence tags) recognized as potential mRNAs. The strategy of identifying proteins by sequence similarity validated all the identifications suggested by MASCOT, and allowed the identification of 14 new proteins not yet described in sugarcane, such as Oxygen evolving complex 1 , Triosephosphate isomerase, Ubiquitin - conjungating, Phosphoglycerate mutase, Fructose bisphosphate aldolase cytoplasmic, 6-phosphogluconate dehydrogenase, Heat shock $70 \mathrm{kDa}$, Frutokinase-1, Ascorbate peroxidase, 3-beta hydroxysteroid dehydrogenase, Ferredoxin NADP reductase, Chlorophyl ab, Nucleic acid binding protein1, and Auxin. These proteins had their expression induced or repressed in the genotypes submitted to water stress.

Genes found in the sugarcane transcriptome were included in functional categories according to the homology of the function of known proteins. These categories are classified into: a) cellular processes; b) photosynthesis; c) bioenergetic; d) cell signal transduction; e) growth; f) response to stress; g) transport; eh) unknown proteins or unclassified categories (Rodrigues et al., 2009). Among the proteins with the sequences identified by mass spectrometry, six showed homology to proteins with still unknown function. As identifications are made through database searches, most of the sequences are deposited from EST sequencing projects. However, some proteins found were hitherto hypothetical sequences, and were classified as if they are from the defined "non-functional" category.

The importance of sugarcane crops is growing lately, mainly in its potential within the context of international bioenergy. The study of and understanding of its metabolism for application in increasing revenue and reducing losses due to (a)biotic stresses is of great importance. Although significant advances have been made in sugarcane using transcriptomics, proteomics studies are progressing at a slow pace in this crop compared with other monocotyledons, mainly due to limited access to genome information (Salvato et al., 2019). The integration of transcriptomics, proteomics and metabolomics data for the characterization of molecular responses may be useful for future studies, especially in the identification of proteins responsible for the control of metabolic pathways related to crop yield (Vital et al., 2017). In this aspect, the mapping of the sugarcane proteome emerges as an indispensable tool. In this study, it was shown that a method of protein extractions from tissues of leaves and roots of sugarcane generates elevated protein extract concentrations, as shown in Table 1. Also, the high quality, reproducibility, and resolution of the 2-DE gels were shown in Figure 2 for method 3 shown. It demonstrates that it is an ideal component to be used in proteomic analysis, regardless of the 2-DE or LC separation technique used prior to mass spectrometry (MS) sequencing.

\section{Materials and methods}

\section{Plant materials}

In the present study we used a cultivar obtained from the sugarcane breeding program of the Federal University of Alagoas. Twenty plants of cultivar RB92579 were grown for 60 days in a greenhouse in $10 \mathrm{~L}$ pots with substrate containing one plant / pot, which were kept at near field capacity with daily evapotranspirated water replenishment. Plants were grown under ideal growth conditions (temperature $31.7 \pm 0.70^{\circ} \mathrm{C}$, relative humidity $65.3 \pm 2.01 \%$ ). Leaf material was collected individually on leaf +1 (youngest leaf first in which the dewlap is already exposed) for each of the main plants contained in each of the cultivated pots, then grouped into four biological replicates, each consisting of a pool of five leaves +1 , totaling twenty plants. On the other hand, the root samples were collected after the leaf material was collected and the whole plants were removed from the pots, removing all the substrate from the root system, followed by the washing of the roots with rapid immersion in cold distilled water. Immediately, the entire root system was cooled with liquid nitrogen with full immersion of the roots to prevent oxidation. Then, the thinner and less woody roots of the peripheral zone were collected with scissors and placed in PVC envelopes containing nitrogen, and then immediately wrapped in styrofoam with nitrogen.

Subsequently, the samples were taken to the laboratory and stored in an ultra-freezer at $-86^{\circ} \mathrm{C}$ until proteome assays were performed.

\section{Protein extraction methods}

The methods of protein extraction from tissue of leaves and roots of sugarcane were analyzed using three methods. Each procedure was performed in three biological replicates.

For all methods tested, leaves and roots were macerated in a mortar previously cooled with liquid nitrogen $2 \%$ PVPP $(w / v)$. Aliquots of the pulverized material (1gram) were immediately transferred to $10 \mathrm{~mL}$ centrifuge tubes and stored at $-80^{\circ} \mathrm{C}$ until their protein extractions were performed.

\section{Method 1. TCA/acetone (control)}

This method was based following modifications of the method described by Damerval et al., (1986). The pulverized material was re-suspended in a buffer containing $50 \mathrm{mM}$ Tris- $\mathrm{HCl}$ ( $\mathrm{pH}$ 7.5), $14 \mathrm{mM}$ ß-mercaptoethanol and $1 \mathrm{mM}$ Phenylmethanesulfonyl fluoride (PMSF). After 10 minutes of constant homogenization on ice, the material was then centrifuged at $10,000 \mathrm{~g}$ at $4^{\circ} \mathrm{C}$ for 15 minutes. The supernatant was transferred to a fresh tube and increased 
to $10 \mathrm{~mL}$ with $10 \%$ trichloroacetic acid (TCA) in acetone and incubated at $20^{\circ} \mathrm{C}$ for 2 hours for protein precipitation. Thereafter, the protein extract was centrifuged at 10,000 g at $4^{\circ} \mathrm{C}$ for 15 minutes. The precipitate was washed with cold $80 \%$ acetone. At each washing step the precipitate was vortexed for 1 minute and centrifuged for 15 minutes at $10,000 \mathrm{~g}$ at 4 으. The precipitate was then dried and stored at $-20^{\circ} \mathrm{C}$ (Damerval et al., 1986).

\section{Method 2. TCA/acetone modified}

This methodology was based on Shen, (2012) with modifications. The pulverized material was re-suspended in extraction buffer containing $40 \mathrm{mM}$ Tris- $\mathrm{HCl}(\mathrm{pH}$ 7.5), polyvinylpolypyrrolidone (PVPP) $0.2 \%(\mathrm{w} / \mathrm{v}), 250 \mathrm{mM}$ sucrose, $10 \mathrm{mM}$ EDTA, triton X-100 1\% (v/v), $1 \mathrm{mM}$ PMSF and $2 \%$ B-mercaptoethanol $(\mathrm{v} / \mathrm{v})$. The sample was vortexed for 1 minute and kept under constant homogenization on ice for 2 hours. The material was then centrifuged at 12,000 g at $4^{\circ} \mathrm{C}$ for 15 minutes and the supernatant was transferred to a new tube and the volume was adjusted to $10 \mathrm{~mL}$ with an extraction buffer. It was then centrifuged again at $12,000 \mathrm{~g}$ at $4^{\circ} \mathrm{C}$ for 15 minutes (Shen, 2012).

The supernatant was then transferred to a new tube and increased to a volume of $10 \mathrm{~mL}$ with a solution of $10 \%$ TCA in acetone. The material was incubated at $20^{\circ} \mathrm{C}$ for 12 hours. Thereafter, the proteins were washed three times in a solution of $10 \%$ TCA/acetone and once in $80 \%$ ethanol. During washing, the material was centrifuged at $12,000 \mathrm{~g}$ at $4^{\circ} \mathrm{C}$ for 15 minutes. The precipitate was then dried and stored at $-20^{\circ} \mathrm{C}$ (Shen, 2012).

\section{Method 3. Phenol/SDS/ammonium acetate modified}

This method was based on Wang et al. (2003) with modifications. The pulverized material was re-suspended in a solution containing $1 \%$ PVPP (w/v), 2\% ß-mercaptoethanol $(\mathrm{v} / \mathrm{v})$ and $1 \mathrm{mM}$ PMSF in cold acetone and kept under constant homogenization on ice for 2 hours. After centrifugation at $12,000 \mathrm{~g} 4^{\circ} \mathrm{C}$ for 15 minutes, the supernatant was discarded and the pellet was washed five times with cold acetone. Then it was dried and freeze dried. The precipitate was washed 4 times with $10 \mathrm{~mL}$ of $10 \%$ TCA in cold acetone and centrifuged at $12,000 \mathrm{~g}$ at $4^{\circ} \mathrm{C}$ for 15 minutes. For each washing step the material was vortexed for 30 seconds, washed 2 times with 10\% TCA in water, washed 2 times in $80 \%$ acetone and once in $80 \%$ ethanol.

For each washing, the precipitate was re-suspended, centrifuged, and then freeze dried. The pellet was resuspended in dense-SDS extraction buffer (30\% sucrose, $2 \%$ SDS, $0.1 \mathrm{M}$ Tris- $\mathrm{HCl}$ ( $\mathrm{pH} 8.0), 1 \mathrm{mM}$ PMSF, and $2 \%$ ßmercaptoethanol $(\mathrm{v} / \mathrm{v}))$. After stirring for 10 minutes at room temperature, tris-saturated phenol $(\mathrm{pH}$ 8.0) buffer was added and stirred on ice for 10 minutes (Wang et al., 2003). Subsequently the sample was centrifuged at $12,000 \mathrm{~g}$ at $4^{\circ} \mathrm{C}$ for 15 minutes and the phenolic fraction was collected and transferred to a new tube. The proteins from the phenolic phase were precipitated by adding 5 volumes of $0.1 \mathrm{M}$ ammonium acetate in methanol and incubated for 12 hours at $-20 \circ \mathrm{C}$. Thereafter the extract was centrifuged at $12,000 \mathrm{~g}$ at $4^{\circ} \mathrm{C}$ for 15 minutes. The recovered precipitate was washed twice in $0.1 \mathrm{M}$ ammonium acetate, twice in $80 \%$ acetone and once more in $80 \%$ ethanol. At each step the precipitate was homogenized and centrifuged at $12,000 \mathrm{~g}$ at $4^{\circ} \mathrm{C}$ for 15 minutes. The precipitate was then dried and stored at $-20^{\circ} \mathrm{C}$ (Wang et al., 2003).

In every method of extraction, the proteins were dissolved in a solubilization buffer containing $7 \mathrm{M}$ urea, $2 \mathrm{M}$ thiourea and $2 \%$ triton $x-100$. The samples were sonicated three times for 30 seconds and centrifuged. The protein samples were stored in aliquots at $-80^{\circ} \mathrm{C}$ (Wang et al., 2003).

\section{One dimensional electrophoresis (SDS-PAGE) and quantification}

For SDS-PAGE, equal amounts (30 mg) of proteins were separated on $12.5 \%$ polyacrylamide gel according to Laemmli, (1970). Proteins were visualized by using $0.1 \%$ Coomassie Brilliant Blue as dye (G250) and protein concentration was determined by using the method described by Bradford, (1976) using albumin (BSA) as the standard.

\section{2-DE, Ccloration of gels and image analysis}

Two-dimensional electrophoresis (2-DE) was performed using Immobiline DryStrip $13 \mathrm{~cm}, \mathrm{pH}$ 3-10 and pH 4-7 (GE Healthcare, Piscataway, NJ), as utilized according to the manufacturer's instructions with slight modifications. For each strip, $800 \mathrm{mg}$ of protein extract re-suspended in $250 \mu \mathrm{l}$ of rehydration buffer $7 \mathrm{M}$ urea, $2 \mathrm{M}$ thiourea, triton $\mathrm{X}-100$ $0.4 \% \mathrm{v} / \mathrm{v}, 4 \%$ chloroamidopropryl dimethylammonio propane sulfonate (CHAPS) w/v, dithiothreitol (DTT) 1\%, IPG buffer $1 \% \mathrm{v} / \mathrm{v}$, Bromophenol Blue $0.05 \%$ and $\mathrm{pH}$ 4-7 (GE Healthcare) were loaded. The resulting materials (roots, leaves) were used for rehydration of the strips for 14 hours at room temperature. The isoelectric focusing was performed using the IPGphor IEF system device (GE Healthcare).

After isoelectric focusing, the strips were equilibrated for 15 minutes in an equilibration buffer (6M Urea, 30\% glycerol, $2 \%$ SDS, $0.002 \%$ bromophenol blue, $50 \mathrm{mM}$ Tris- $\mathrm{HCl}, \mathrm{pH}$ 6.8) containing $10 \mathrm{mg} / \mathrm{ml}$ of DTT and 15 minutes in equilibration buffer containing $25 \mathrm{mg} / \mathrm{ml}$ of iodoacetamide.

The strips were then washed with water and the second dimension was done on $12 \%$ SDS-PAGE on an Amersham Hoefer SE600 system (GE Healthcare), with a pre-run of 15 $\mathrm{mA} /$ gel $30 \mathrm{~mA} /$ gel for 30 minutes and $30 \mathrm{~mA} /$ gel for 6 hours at $15^{\circ} \mathrm{C}$. The gels were stained with Coomassie Brilliant Blue G-250 and digitalized by a high-precision scanner (GE Healthcare) and analyzed with Image Master 2D platinum program (v. 7.0, GE).

The spots were manually excised from the gels and placed in $1.5 \mathrm{~mL}$ microtubes previously washed with methanol, sealed and stored at $-80^{\circ} \mathrm{C}$. The spots were digested and analyzed by Mass Spectrometer MALDI TOF/TOF (Autoflex III SmartBeam, Handelsregister Bruker Daltonics, Bremen, Germany). The database searches done from the spectrometric (MS and MS / MS) information obtained by MALDI TOF/TOF were used in determining the identity of the proteins with the MASCOT tool (www.matrixscience.com). 
The spectra generated were compared with data that was deposited at the National Center for Biotechnology Information (NCBI, http://ncbi.nlm.nih.gov / BLAST) and SUCEST library (www.suceste-fun.org).

Pools were made from the tissue extracted from four plants. The proteins were extracted in combined procedures using acetone/ammonium acetate - methanol and the extraction with phenol / SDS using the method based on Wang et al. (2003).

The proteins were extracted in combined procedures by acetone / ammonium acetate - methanol and phenol / SDS extraction by the Wang - based method (Wang et al., 2003).

\section{Conclusions}

Although proteomics is characterized as a powerful tool, studies involving proteomics of sugarcane are still poorly performed when compared to other plant species whose genomic studies are already in much more advanced stages. Moreover, these studies with this culture mostly have been based on information contained in collections of ESTs derived from transcriptomic studies applied to different tissues. Consequently, specific protocols for the extraction of proteins from tissues of sugarcane are scarce.

In this study, 3 different extraction methods of proteins from leaf and root tissue were adapted from other plant species protocols, and their applications to 2-DE and MS were tested. Among the methods used, the method using phenol / SDS / ammonium acetate (method 3) showed the higher amount of extracted proteins per fresh tissue for leaves and roots tissues.

When submitted to 2-DE, the gels obtained by method 3 showed the higher number of spots distributed evenly throughout the gel, with excellent migration quality without stains or smears. Therefore, the use of this method was efficient in the removal of contaminants interfering in both IEF and SDS-PAGE. In addition, most spots submitted to mass spectrometry were successfully identified.

The importance of sugarcane crops is growing lately, mainly in its potential within the context of international bioenergy. In this aspect the mapping of the sugarcane proteome emerges as an indispensable tool. In this study it was shown that the method of protein extraction phenol / SDS / ammonium acetate (method 3) from tissues of leaves and roots of sugarcane presented better results in the extractions of proteins and in the 2-DE gels, with a greater number of total and specific "spots", greater reproducibility and less background. This method could be utilized as the standard method for proteomic studies in sugarcane.

\section{Acknowledgements}

This research was carried out by the financial support in the form of grants and fellowship awards by the Brazilian National Research Council (CNPq), FAPEAL (Fundação de Amparo à Pesquisa do Estado de Alagoas) and CAPES (Coordenação de Aperfeiçoamento de Pessoal de Nível superior.
References

Agrawal GK, Bourguignon J, Rolland N, Ephritikhine G, Myriam $F$, Jaquinod $M$, Alexiou $K$ G, Chardot $T$, Chakraborty N, Jolivet P, Doonan JH, Rakwal R (2011) Plant organelle proteomics: collaborating for optimal cell function. Mass Spectrom Rev. 30:772-853.

Bradford MM (1976) A rapid and sensitive method for the quantitation of microgram quantities of protein utilizing the principle of protein-dye binding. Analytical Biochemistry. 248-254.

Crozier A, Jensen E, Lean MEJ, McDonald MS \& Black C (1997) Quantitative analysis of the flavonoid content of commercial tomatoes, onions, lettuce and celery. Journal of Agriculture and Food Chemistry. 45:590-595.

Damerval C, DE Vienne D, Zivy M, Thiellement H (1986) Technical improvements in two-dimensional electrophoresis increase the level of genetic variation detected in wheat-seedling proteins. Electrophoresis. 7:52-4.

Dooki AD, Mayer-Posner FJ, Askari H, Zaiee A and Salekdeh $\mathrm{GH}$ (2006) Proteomic responses of rice young panicles to salinity. Proteomics. 6:6498-6507.

Gang D, Xinyue Z, Na Z, Chengying L, Bo W (2014) A Proteomics Sample Preparation Method for Mature, Recalcitrant Leaves of Perennial. PLOS ONE. 9(7).

Goez MM, Torres-Madroñero MC, Röthlisberger S, Delgado-Trejos E (2018) Preprocessing of 2-Dimensional Gel Electrophoresis Images Applied to Proteomic Analysis: A Review. Genomics, Proteomics Bioinforma. 16:63-72.

Görg A, Carsten L, Weiss W (2008) Sample prefractionation in granulated sephadex IEF gels. Methods in molecular biology. 424:277-86.

Gygi SP, Corthais GL, Zhang Y, Aebersold R (2000) Evaluation of two-dimensional gel electrophoresis-based proteome analyses technology. Proceeding of the National Academic of Sciences of the United States of America, Washington. 97:9390-9395.

He CF and Wang YM (2008) Protein extraction from leaves of Aloe vera L., a succulent and recalcitrant plant, for proteomic analysis. Plant Molecular Biology Reporter. 26:292-300.

Herbert B (1999) Advances in protein solubilisation for two-dimensional electrophoresis. Electrophoresis. 20:660-663.

Hu J, Rampitsch C, Bykova NV (2015) Advances in plant proteomics toward improvement of crop productivity and stress resistance. Frontiers in Plant Science. 6:209.

Isaacson T, Damasceno CMB, Saravanan RS, He Y, Catalá C, Saladié M (2006) Simple extraction techniques for enhanced proteomic analysis of plant tissues. Nat Prot. 1:769-74.

Jorrin-Novo JV, Pascual J, Lucas RS, Romero-Rodríguez MC, Rodríguez-Ortega MJ, Lenz C, Valledor L (2015) Fourteen years of plant proteomics reflected in "Proteomics": moving from model species and 2-DE based approaches 
to orphan species and gel-free platforms. Proteomics. 15:1-45.

Komatsu, S (2019) Plant Proteomic Research 2.0: Trends and Perspectives. Int J Mole Sci. 20:2495.

Laemmli, UK (1970) Cleavage of structural proteins during the assembly of the head of bacteriophage T4. Nature. 227:680-68.

Li K, Xu C, Zhang K, Yang A, Zhang J (2007) Proteomic analysis of roots growth and metabolic changes under phosphorus deficit in maize (Zea mays L.) plants. Proteomics. 7:1501-1512.

Magdeldin T, López-Dávila V, Villemant C, Cameron G, Drake R, Cheema U (2014) The efficacy of cetuximab in a tissue-engineered three-dimensional in vitro model of colorectal cancer. J Tissue Eng. 5:1-9.

Maranho RC, Benez MM, Maranho GB, de Azevedo Fernandes VN, Gonela A, Mangolin CA, \& da Silva Machado M de FP (2018) Extraction of Total Protein from Axillary Buds of Sugarcane (Saccharum spp.) for Proteomic Analysis. Sugar Tech. 20(1):95-99.

Niu L, Yuan H, Gong F, Wu X, Wang W (2018a) Protein extraction methods shape much of the extracted proteomes. Front Plant Sci. 9:802.

Niu L, Zhang H, Wu Z, Wang Y, Liu H, Wu X (2018b) Modified TCA/acetone precipitation of plant proteins for proteomic analysis. PLoS ONE. 13:12.

Pavokovic' D, Križnik B, Krsnik-Rasol M (2012) Evaluation of protein extraction methods for proteomic analysis of non-model recalcitrant plant tissues. Croatica Chemica Acta. 85:177-183.

Pryor SW, Smithers J, Lyne P, \& van Antwerpen R (2017) Impact of agricultural practices on energy use and greenhouse gas emissions for South African sugarcane production. Journal of Cleaner Production. 141:137-145.

Raharjo TJ, Widjaja L, Roytrakul S, Verpoorte R (2004) Comparative proteomics of Cannabis sativa plant tissues. Journal of Biomolecular techniques. 15:97-106.
Rodrigues FA, Laia ML, Zingaretti SM (2009) Analysis of gene expression profiles under water stress in tolerant and sensitive sugarcane plants. Plant Science. 176:286302.

Saravanan RS, Rose JKC (2004) Proteomics. 4:2522- 2532.

Shen S (2002) A proteomic analysis of leaf sheaths from rice. J Biochem. 132: 613-620.

Vetorre AL, Silva FR, Kemper EL, Arruda P (2001) The libraries that made SUCEST. Genet Mol Biol. 24:1-4.

Vital CE, Giordano A, de Almeida Soares E, Rhys Williams TC, Mesquita RO, Vidigal PMP, de Santana Lopes A, Pacheco TG, Rogalski M, de Oliveira Ramos HJ, Loureiro ME (2017) An integrative overview of the molecular and physiological responses of sugarcane under drought conditions. Plant Mole Biol. 94: 577-594.

Wang W, Scali M, Vignani R, Spadafora A (2003) Electrophoresis. 24: 2369-2375.

Wang. W, Vignani R, Scali M, Cresti M (2006) Electrophoresis. 27:2782-6.

Wang W, Tai F, Chen S (2008) Optimizing protein extraction from plant tissues for enhanced proteomics analysis. J Sep Sci. 31:2032-9.

Xu C, Sullivan JH, Garrett WM, Caperna TJ, Natarajan S (2008) Impact of solar ultraviolet-B on the proteome in soybean lines differing in flavonoid contents. Phytochemistry. 69:38-48.

Zhou G, Li H, DeCamp D, Chen S, Shu H, Gong Y, Flaig M, Gillespie JW, Hu N, Taylor P R, Emmert-Buck MR, Liotta LA, Petricon EF, Zhao Y (2002) 2D differential in-gel electrophoresis for the identification of esophageal scans cell cancer-specific protein markers. Mol Cell Proteomics. 1:117-124. 